\title{
EFEKTIVITAS NUTRISI AB MIX TERHADAP HASIL DUA VARIETAS MELON
}

\author{
[The Effectivity of AB Mix Nutrient For Yield of Two Melon Varieties] \\ Nanik Furoidah \\ Fakultas Pertanian, Universitas Islam Jember \\ email: florida_nanik@yahoo.co.id
}

\begin{abstract}
ABSTRAK
Tujuan dari penelitian ini adalah untuk mendapatkan konsentrasi yang efisien dari larutan nutrisi $\mathrm{AB}$ Mix siap pakai untuk pertumbuhan dan kualitas hasil dari dua varietas melon. Penelitian ini menggunakan rancangan acak lengkap. (RCD) dengan pola faktorial $2 \times 2$ diulang 4 kali. Faktor I perlakuan konsentrasi nutrisi $\mathrm{AB}$ Mix $(\mathrm{N})$ yang terdiri dari $\mathrm{N} 1=1600 \mathrm{ppm}, \mathrm{N} 2=1800 \mathrm{ppm}$ sedangkan perlakuan Faktor II varietas melon (V) terdiri dari V1 = Alexandro, dan V2 = Melani. Data yang diamati dianalisis dengan ANOVA dan perlakuan secara signifikan berbeda dalam uji F 5\% oleh Duncan 5\% tes tindak lanjut. Indikator keberhasilan pertumbuhan dan kualitas hasil melon dengan memberikan larutan nutrisi Mix AB pada konsentrasi tertentu dapat dilihat dari parameter yang diamati meliputi: jumlah bunga, berat buah, volume buah, ketebalan daging buah dan kandungan gula melon (brix) yang ditunjukkan oleh kuantitatif data. Dari hasil penelitian didapat kesimpulan bahwa konsentrasi AB Mix 1800 ppm memberikan hasil terbaik pada melon var. Alexandro pada parameter jumlah bunga, berat buah, volume buah, dan ketebalan daging buah, sebaliknya untuk hasil terbaik varietas Melani pada parameter di atas diperoleh pada konsentrasi $1600 \mathrm{ppm}$. , tetapi untuk kandungan gula tertinggi (brix) di Alexandro diperoleh pada konsentrasi 1600 ppm, tetapi varietas Melani pada 1800 ppm.
\end{abstract}

Kata kunci: buah melon, hasil, hidroponik, konsentrasi nutrisi.

\begin{abstract}
The objective of this research was to obtain an efficient concentration of ready-touse $A B$ Mix nutrient solution for growth and yield quality from two melon varieties. This study used a complete randomized design (RCD) with $2 \times 2$ factorial pattern repeated 4 times. Factor I treatment of nutrient concentration of AB Mix $(N)$ consisting of $N 1=1600 \mathrm{ppm}, \mathrm{N} 2=1800 \mathrm{ppm}$ while Factor II treatment of melon variety $(V)$ consisted of $V 1=$ Alexandro, and $V 2=$ Melani. The observed data were analyzed with ANOVA and the treatment was significantly different in the F 5\% test by Duncan 5\% follow-up test. Indicators of successful growth and quality of melon yields by giving $A B$ Mix nutrient solution at certain concentrations can be seen from the parameters observed include: number of flowers, fruit weight, fruit volume, fruit flesh thickness and melon sugar content (brix) indicated by quantitative data. From the results of the study obtained the conclusion that the concentration of $A B$ Mix 1800 ppm gives the best results on melon var. Alexandro on the parameters of the number of flowers, the weight of
\end{abstract}


fruit, the volume of fruit, and the thickness of the fruit flesh, on the contrary for the best results of Melani varieties on the above parameters were obtained at a concentration of 1600 ppm, but for the highest sugar content (brix) in Alexandro were obtained at a concentration of $1600 \mathrm{ppm}$, but Melani varieties at $1800 \mathrm{ppm}$.

Key words: melon fruit, yield, hydroponics, nutrient concentration

\section{PENDAHULUAN}

Di Indonesia buah melon termasuk buah yang diminati banyak orang, dan mempunyai pasar yang cukup bagus meski harganya tergolong tinggi dibanding harga rata-rata buah sejenis. Oleh karena itu konsumsi buah melon terus bertambah dari tahun ke tahun yang sangat mendukung perkembangan melon di Indonesia.Pada tahun 2010, produksi melon di Indonesia hanya sebesar 85.161 ton sehingga tidak dapat memenuhi kebutuhan melon di dalam negeri.Akibatnya 247.537 ton buah melon harus diimpor dari luar negeri (BPS, 2012).

Peningkatan kebutuhan akan buah melon seharusnya diiringi dengan pertambahan lahan budidaya, namun ironisnya jumlah lahan produktif untuk kegiatan pertanian di wilayah perkotaan Kabupaten Jember pada sepuluh tahun terakhir banyak beralih fungsi pada sektor perdagangan, industri, pariwisata, perumahan serta jasa. Kabupaten Jember dengan berbagai macam komoditi pertaniannya, memiliki beberapa keunggulan yang tidak dimiliki daerah lain. Namun sayang, potensi yang dimiliki Kabupaten Jember ini, belum sepenuhnya bisa memberikan kontribusi besar terhadap upaya peningkatan pendapatan petaninya.

Upaya untuk mengatasi terbatasnya lahan dari tahun ke tahun seiring dengan meningkatnya jumlah penduduk tiap tahun serta untuk peningkatan pendapatan petani buah khususnya di Kabupaten Jember adalah dengan pemilihan teknik budidaya alternatif yaitu hidroponik yaitu budidaya tanpa tanah.Prinsipnya adalah penekanan padakonsep produksitanaman secaraberkelanjutan, tidak terkendala oleh musimdengan menerapkan teknologi energi bersih (clean energy technologies) (Nurlaeny, 2014). Dari pengertian ini terlihat bahwa munculnya teknik bertanam secara hidroponik diawali oleh semakin tingginya perhatian manusia akan pentingnya kebutuhan pupuk bagi tanaman serta semakin 
berkurangnya lahan produktif untuk bercocok tanam.Bertanam secara hidroponik di perkotaan sebagai solusi paling mudah, murah dan ramah lingkungan (ecofarming) serta membentuk komunitas petani perkotaan untuk meningkatkan produksi buah lokal dan menjadikan Jember sebagai sentra buah.

Bertanam melon dengan metode hidroponik cukup pupuler dan banyak diminati oleh masyarakat beberapa tahun belakangan ini, dimana kualitas buah yang dihasilkan lebih tinggi sehingga harga jualnya menjadi lebih tinggi pula.Teknik hidroponik ini mampu meningkatkan hasil tanaman persatuan luas sampai lebih dari sepuluh kali, bila dibandingkan dengan teknik pertanian konvensional (Soenoeadji,1990 cit. Basuki,2008). Keunggulan lainnya adalah pengontrolan terhadap kesehatan dan perkembangan tanaman lebih mudah, bebas dari serangan hama dan penyakit serta memungkinkan untuk melakukan pembibitan di luar musim.

Bertanam hidroponik sangat bergantung pada sumber nutrisi dari bahan kimia / organik terlarut, lingkungan yang sehat bagi akar, $\mathrm{pH}$ air dan oksigen terlarut (Fathulloh, A.S, dkk, 2016).Menanam dengan teknik hidroponik harus memperhatikan pemenuhan kebutuhan nutrisi bagi tanaman, dimana kandungan unsur hara makro dan mikronya harus tercukupi. Setiap jenis nutrisi hidroponik mempunyai komposisi yang berbeda-beda. Ukuran konsentrasi larutan yang sesuai sangat berpengaruh terhadap pertumbuhan melon dan produksinya. Sekarang ini sangat mudah diperoleh formulasi instan nurisi hidroponik di pasaran yang dikenal dengan $\mathrm{AB}$ mix, tetapi belum direkomendasikan konsentrasi yang tepat untuk melon (masih sebatas range/kisaran).Untuk itu perlu dilakukan penelitian konsentrasi yang tepat sesuai kebutuhan melon untuk pertumbuhan dan perkembangan melon yang optimal.

\section{METODE PENELITIAN}

Penelitian ini dilakukan di Green House, Agroteknologi, Faultas Pertanian Universitas Islam Jember mulai bulan Pebruari sampai dengan Mei 2017. Penelitian ini dimulai dengan penyemaian benih melon pada rockwool, kemudian bibit yang sudah muncul minimal tiga daun ditanam didutch bucket pada instalasi hidroponik sirkulasi, dimana hasilnya dapat dipanen pada umur 90 hari setelah 
tanam (HST).Desain dalam penelitian digunakan Rancangan Acak Lengkap Faktorial 2 x 2 dengan ulangan 4 kali. Faktor I perlakuan varietas melon (V) terdiri dari 2 taraf yaitu V1 var. Alexandro dan V2 var. Melani; Faktor II perlakuan konsentrasi AB Mix (N) terdiri 2 taraf yaitu 1600 ppm (N1) dan 1800 ppm (N2). Data pengamatan dianalisa dengan ANOVA dan untuk perlakuan yang berbeda nyata pada uji F 5\% dilakukan uji lanjutan Duncan 5\%. Indikator keberhasilan pertumbuhan dan kualitas hasil melon dengan pemberian larutan nutrisi AB Mix pada konsentrasi tertentu dapat dilihat dari parameter yang diamati meliputi: jumlah bunga, berat buah, volume buah, tebal daging buahdan kadar gula (brix) melon yang ditunjukkan dengan data kuantitatif.

Indikator keberhasilan pertumbuhan dan kualitas hasil melondengan pemberian larutan nutrisi AB Mix pada konsentrasi tertentu dapat dilihat dari parameter yang diamati meliputi: jumlah bunga, berat buah, volume buah, tebal daging buahdan kadar gula (brix) melon yang ditunjukkan dengan data kuantitatif.

\section{HASIL DAN PEMBAHASAN}

\section{Rangkuman F Hitung dan Uji Duncan pada Semua Parameter Melon}

Hasil data pengamatan penelitian tiap parameter yang dianalisa keragamannya (ANOVA) diperoleh nilai F hitung sebagai berikut pada Tabel 1.

Tabel 1. Rangkuman Uji F Hitung pada Seluruh Parameter Pengamatan Melon

\begin{tabular}{|c|c|c|c|c|c|c|c|}
\hline \multirow{3}{*}{$\begin{array}{c}\text { Sumber } \\
\text { Keragaman }\end{array}$} & \multicolumn{6}{|c|}{ Nilai F Hitung } & \multirow{3}{*}{$\begin{array}{c}F \\
\text { Tabel } \\
5 \%\end{array}$} \\
\hline & \multicolumn{2}{|c|}{ Jumlah Bunga } & \multirow{2}{*}{$\begin{array}{l}\text { Berat } \\
\text { Buah }\end{array}$} & \multirow{2}{*}{$\begin{array}{l}\text { Volume } \\
\text { Buah }\end{array}$} & \multirow{2}{*}{$\begin{array}{c}\text { Tebal } \\
\text { daging } \\
\text { buah }\end{array}$} & \multirow{2}{*}{$\begin{array}{c}\text { Kadar } \\
\text { gula / } \\
\text { brix }\end{array}$} & \\
\hline & q & 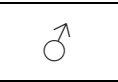 & & & & & \\
\hline V & $1,93^{\mathrm{ns}}$ & $7,01^{\mathrm{ns}}$ & $1,51^{\mathrm{ns}}$ & $3,55^{\text {ns }}$ & $5,61^{*}$ & $0,08^{\text {ns }}$ & 4,35 \\
\hline $\mathrm{N}$ & $0,11^{\mathrm{ns}}$ & 0,49 ns & $0,28^{\mathrm{ns}}$ & $0,44^{\mathrm{ns}}$ & $0,33^{\mathrm{ns}}$ & $1,36^{\mathrm{ns}}$ & 4,35 \\
\hline $\mathrm{V} \times \mathrm{N}$ & $13,63^{*}$ & $3,91^{\mathrm{ns}}$ & $1,07^{\mathrm{ns}}$ & $0,25^{\mathrm{ns}}$ & $2,08^{\mathrm{ns}}$ & $1,07^{\mathrm{ns}}$ & 4,35 \\
\hline & $\begin{array}{l}\mathrm{V}=\mathrm{V} \\
\text { interaksi }\end{array}$ & tas me & & & & & $\begin{array}{l}\mathrm{x} \mathrm{N}= \\
\text { hyata; * }\end{array}$ \\
\hline
\end{tabular}

Berdasarkan hasil uji ANOVA (Tabel 1) menunjukkan bahwa terjadi interaksi yang nyata antara dua varietas melon (Alexandro dan Melani) dengan konsentrasi nutrisi $\mathrm{AB}$ Mix yang diberikan pada jumlah bunga betina yang 
dihasilkan yaitu $\mathrm{F}$ hitung 13,63 dan $\mathrm{F}$ tabel $(\alpha 0,05)$ 4,35 tetapi pada variabel pengamatan pasca panen melon (berat buah, volume buah, diameter buah, tebal daging dan kadar gula) menunjukkan tidak terjadi saling pengaruh antar melon var. Alexandro dan var. Melani terhadap konsentrasi AB Mix yang diberikan. Perbedaan pengaruh yang tidak nyata pada variabel pasca panen melon lebih disebabkan oleh perbedaanfaktor genetik bukan karena perbedaan kosentrasi AB Mix yang diberikan.

\section{Jumlah Bunga}

Hasil uji Duncan $\alpha$ 0,05 (Tabel 2) menunjukkan bahwa selisih rata-rata jumlah bunga betina yang dihasilkan melon var. Alexandro (4,60 kuntum) dan var. Melani (3,57 kuntum) berbeda nyata terhadap pemberian konsentrasi nutrisi AB Mix 1800 ppm dan 1600 ppm. Hal ini menunjukkan bahwa untuk menstimulasi terbentuknya bunga betina yang lebih banyak pada melon var. Alexandro dibutuhkan nutrisi $\mathrm{AB}$ Mix yang lebih pekat dibanding var. Melani (Gbr 1).Menurut Hendra, dkk (2014) fosfor merupakan sumber energi bagi tanaman dan mineral ini berperan dalam proses pertumbuhan bunga, buah dan biji sehingga sangat dibutuhkan pada fase perumbuhan generatif. Fosfor jugamemacu pembentukan akar yang berpengaruh terhadap kemampuan akar dalam mengabsorbsi nutrisi yang tersedia untuk pembentukan jumlah bunga. Melon var. Alexandro lebih responsif terhadap pemberian nutrisi AB Mix dengan konsentrasi yang lebih pekat yaitu 1800 ppm dibanding var. Melani. Fosfor diserap akar tanaman dalam bentuk $\mathrm{H}_{2} \mathrm{PO}_{6}$ dan $\mathrm{HPO}_{4}$ dimana di dalam tanaman sebagian fosfor terikat dalam senyawa organik berupa zat pembangun.

Gambar 1 memperlihatkan bahwa jumlah bunga betina dan jantan terbanyak (6 dan 30,33 kuntum), terdapat pada melon var. Alexandro dengan pemberian konsentrasi nutrisi AB Mix 1800 ppm tetapi untuk maelon var. Melani jumlah bunga betina dan jantan terbanyak (4,6 dan 21,33 kuntum) diperoleh pada konsentrasi nutrisi 1600 ppm. 
Tabel 2. Interaksi Varietas Melon dan Konsentrasi AB Mix terhadap Jumlah Bunga Betina

\begin{tabular}{ccc}
\hline \multirow{2}{*}{ Varietas } & \multicolumn{2}{c}{ Konsentrasi $(\mathrm{ppm})$} \\
\cline { 2 - 3 } & 1600 & 1800 \\
\hline \multirow{2}{*}{ Alexandro } & $2.20 \mathrm{~b}$ & $4.60 \mathrm{a}$ \\
& $\mathrm{B}$ & $\mathrm{A}$ \\
Melani & $3.57 \mathrm{a}$ & $1.57 \mathrm{~b}$ \\
& $\mathrm{~A}$ & $\mathrm{~B}$ \\
\hline
\end{tabular}

Keterangan: Notasi huruf kapital membandingkan nilai antar baris dalam kolom yang sama. Notasi huruf kecil membandingkan nilai antar kolom dalam baris yang sama.

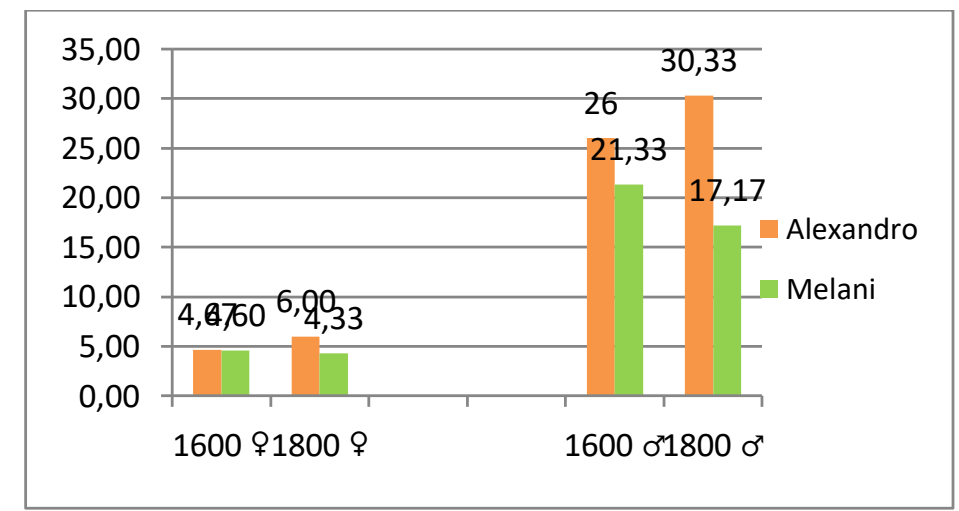

Gambar 1. Pengaruh konsentrasi AB Mix dan varietas melon terhadap jumlah bunga $q \&{ }^{\pi}$

Hal ini menunjukkan produksi jumlah bunga betina dan jantan pada setiap varietas melon memberikan respon yang berbeda terhadap konsentrasi nutrisi $A B$ Mix yang diberikan.Secara genetik melon Alexandro lebih responsif terhadap pemberian nutrisi $\mathrm{AB}$ Mix yang lebih pekat dalam memproduksi bunga betina dan jantan. Perbandingan jumlah bunga betina dan jantan yang terbentuk pada var. Alexandro adalah 1:4 sedangkan pada var. Melani 1:5. Perbandingan ini menunjukkan keberhasilan penyerbukan pada var. Melani lebih tinggi daripada var. Alexandro karena peluang pollen yang jatuh di atas kepala putik lebih banyak.

\section{Pengaruh Konsentrasi AB Mix terhadap Kualitas Buah Dua Varietas Melon}

Kualitas buah melon dapat dilihat dari karakteristik morfologi dan biokimia dari buah yang meliputi antara lain berat buah, volume buah, tebal daging buah dan gula padatan (kadar gula / brix). 
Tabel 3. Uji Duncan 5\% pengaruh konsentrasi nutrisi AB Mix terhadap kualitas hasil dua varietas melon

\begin{tabular}{|c|c|c|c|c|}
\hline Perbandingan & $\mathrm{BB}$ & VB & TD & KG \\
\hline \multicolumn{5}{|l|}{ Varietas V } \\
\hline Alexandro & $1631,60^{\mathrm{a}}$ & $48478,20^{\mathrm{a}}$ & $3,76^{\mathrm{a}}$ & $8.19^{\mathrm{a}}$ \\
\hline Melani & $1856,86^{\mathrm{a}}$ & $59419,15^{\mathrm{a}}$ & $4,23^{\mathrm{a}}$ & $7,98^{\mathrm{a}}$ \\
\hline \multicolumn{5}{|c|}{ Konsentrasi AB Mix (N) } \\
\hline 1600 ppm & $1695,67^{\mathrm{a}}$ & $52015,00^{\mathrm{a}}$ & $3,94^{\mathrm{a}}$ & $8,52^{\mathrm{a}}$ \\
\hline 1800 ppm & $1792,79^{\mathrm{a}}$ & $55882,35^{\mathrm{a}}$ & $4,05^{\mathrm{a}}$ & $7,64^{\mathrm{a}}$ \\
\hline Interaksi V x N & - & - & - & - \\
\hline
\end{tabular}

Proses perkembangan tanaman melon hidroponik pada fase generatif dipengaruhi oleh berbagai faktor antara lain sifat genetik, nutrisi yang tersedia, kemampuan absorbsi perakaran tanaman, oksigen, $\mathrm{pH}$ larutan serta pengaruh eksternal lainnya seperti temperatur, kelembaban udara, intensitas cahaya serta angin.

Hasil panen pada semua variabel pengamatan menunjukkan tidak terdapat interaksi pada dua jenis varietas melon yang diteliti terhadap konsentrasi AB Mix, namun peningkatan konsentrasi nutrisi AB Mix sampai 1800 ppm dapat menaikkan berat buah, volume buah, ketebalan daging buah pada melon var. Alexandro; hal ini berlawananan dengan respon var. Melani yaitu setiap pengurangan konsentrasi AB Mix 200 ppm akan menaikkan berat buah, ketebalan daging buah, dan kadar gula buah sedangkan kedua Varietas melon akan mengalami kenaikan volume buah pada penambahan konsentrasi nutrisi yang diberikan (Gambar 1).

Hasil penelitian menunjukkan bahwa berat buah melon var. Melani sesuai dengan diskripsi pada label kemasan Benih Asia yaitu 1-2 kg, dan varietas ini terbukti di lapang toleran terhadap penyakit kresek (mildew powder). Namun berat buah pada var. Melani cenderung berkurang pada level konsentrasi 1800 ppm, hal ini menunjukkan konsentrasi nutrisi AB Mix 1600 ppm merupakan level optimal bagi var. Melani secara fisiologis dalam memenuhi mineral hara yang diperlukan untuk pertumbuhan buah dan biji terutama fosfor dan kalium yang berperan dalam asimilasi karbohidrat pada proses fotosintesis. Sobir dan Siregar (2010) menyatakan bahwa pupuk kalium mendukung pertumbuhan tanaman, pembungaan dan pembentukan buah. 


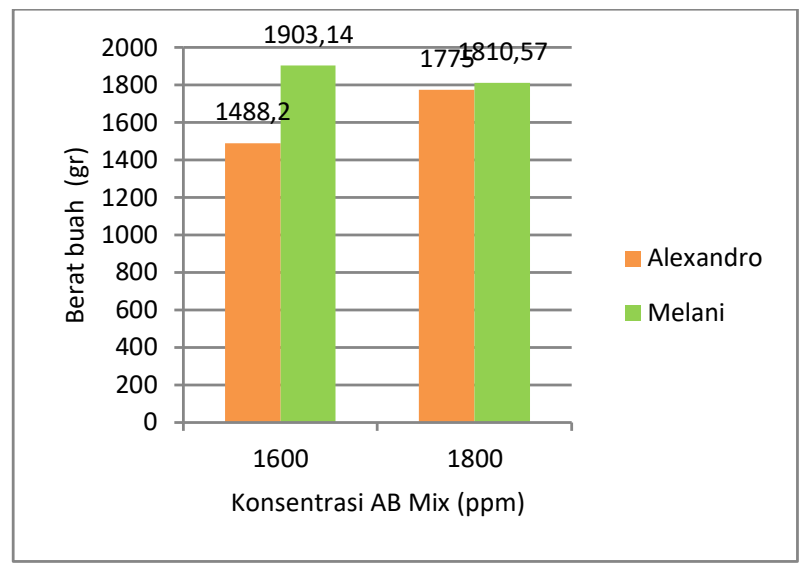

Gambar 2. Pengaruh konsentrasi AB Mix dan varietas melon terhadap berat buah

Berat buah melon var. Alexandro yang dihasilkan pada penelitian ini rata-rata 1,5 - 1,8 kg dan tidak sesuai dengan diskripsi perusahaan "CV Aura Seed Indonesia, Kediri" yaitu $3-4 \mathrm{~kg}$. Hal ini diduga buah melon yang ditinggalkan di pohon sebanyak tiga biji menyebabkan fotosintat hasil fotosintesis terbagi penyalurannya pada ketiga buah tersebut sehingga petumbuhan buah tidak optimal selain itu faktor eksternal dimana temperature udara rata-rata di siang hari $31^{\circ} \mathrm{C}$ dan mendung pada sore, kelembaban udara berpengaruh pada pembentukan buah. Meskipun pemberian nutrisi AB Mix makin pekat akan meningkatkan berat buah pada var. Alexandro tetapi masih jauh dari berat standar. Sifat var. Alexandro yang lebih responsif terhadap nutrisi AB Mix disebabkan faktor genetik.

Berat buah, volume buah, tebal daging buah pada kedua varietas melon cenderung meningkat sesuai penambahan nutrisi $\mathrm{AB}$ Mix (Gbr 2-4) meskipun perbedaannya tidak nyata (Tabel 1). Pada variabel kadar gula, melon var. Alexandro cenderung meningkat pada konsentrasi AB Mix 1600 ppm sebaliknya kadar gula var. Melani semakin meningkat sesuai dengan kenaikan konsentrasi nutrisi yang diberikan meskipun kadar gula yang dihasilkan tetap rendah yaitu pada kisaran $7-9 \%$ (Gbr 5). Diskripsi kadar gula var. Alexandro pada label $14-16 \%$ dan var. Melani 15\%. 


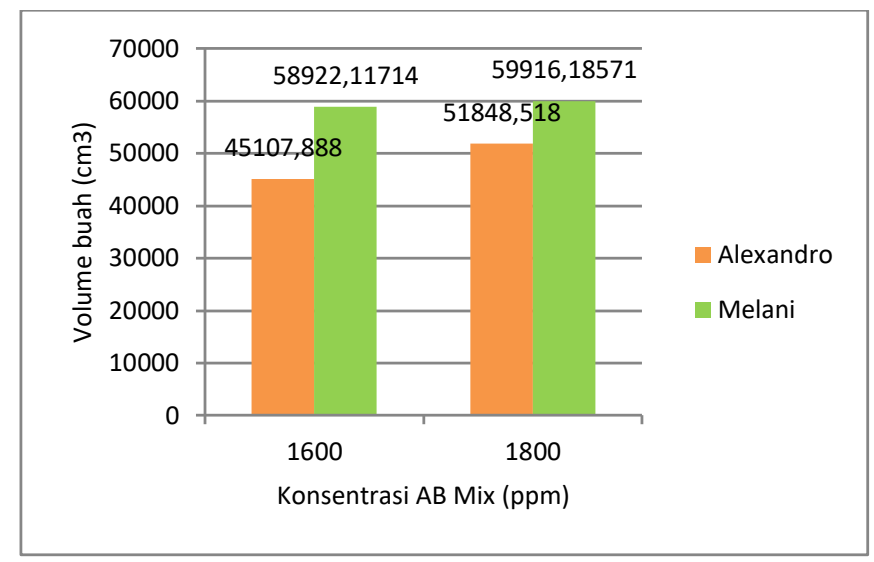

Gambar 3. Pengaruh konsentrasi AB Mix dan varietas melon terhadap volume buah

Hal ini diduga pengaruh lingkungan di luar Green House pada saat penelitian musim hujan dan seringmendung.Pada umumnya melon ditanam pada saat musim kemarau, karena kondisi iklim pada musim kemarau lebih menguntungkan dibanding musim hujan.

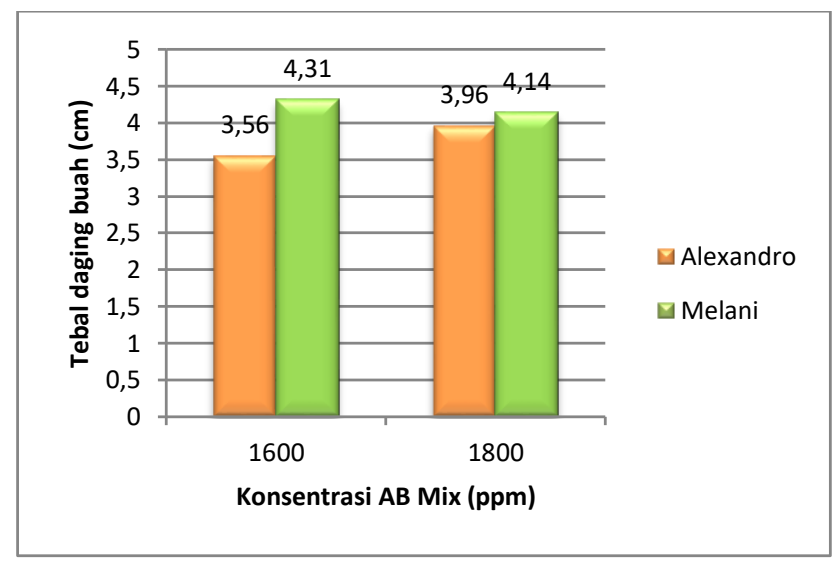

Gambar 4. Pengaruh konsentrasi AB Mix dan varietas melon terhadap tebal daging buah

Untuk pertumbuhan optimal, melon membutuhkan kondisi iklim yang sesuai yaitu suhu udara yang tinggi dan relatif kering serta sinar matahari penuh (Siswanto, 2010), Pada musim hujan suhu udara menurun, kelembaban udara relatif mening a musim akat (lebih basah), radiasi matahari dan panjang penyinaran berkurang karena cuaca sering berawan. Dengan demikian kondisi iklim pada musim hujan dapat menyebabkan gangguan pertumbuhan melon dan dapat menurunkan hasil, baik kuantitas maupun kualitas.Selain itu pertumbuhan dan perkembangan tanaman melon juga ditentukan oleh faktor genetik, yakni varietas yang ditanam (Siswanto, 2010). 


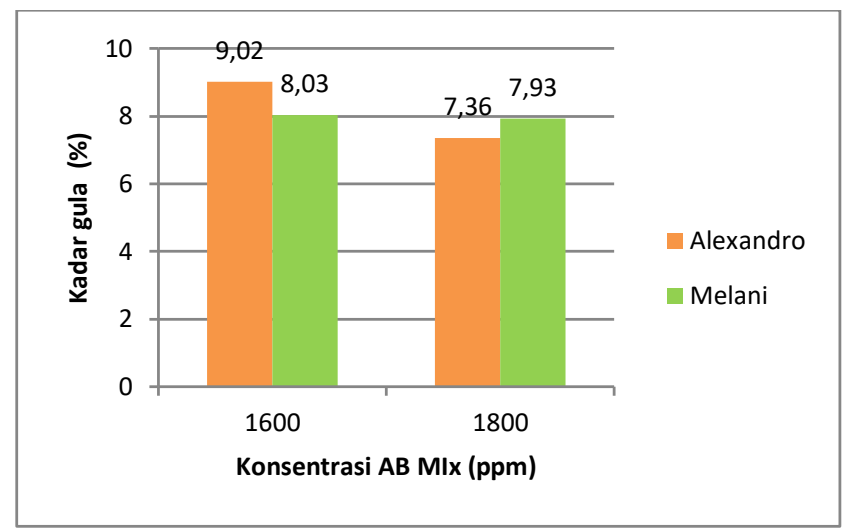

Gambar 5. Pengaruh konsentrasi AB Mix dan varietas melon terhadap kadar gula buah

Pemberian nutrisi AB Mix pada konsentrasi 1600 ppm dan 1800 ppm memungkinkan kedua varietas melon mendapatkan nutrisi yang dibutuhkan. Penelitian Rohmawati, dkk (2007) menunjukkan bahwa pemberian dosis pupuk urea, TSP dan $\mathrm{KCl}$ meningkatkan diameter batang, tingka kehijauan daun, kandungan nitrogen, bobot buah, volume buah dan perlakuan $1 / 2$ kali dosis anjuran memberikan hasil yang lebih baik pada bobot buah, diameter buah dan ketebalan buah.

\section{KESIMPULAN}

1. Pertumbuhan generatif (jumlah bunga betina) dan kualitas hasil melon var. Alexandro (berat buah, volume buah, tebal daging) yang paling baik terdapat pada konsentrasi nutrisi AB Mix 1800 ppm dan var. Melani pada 1600 ppm. Untuk kadar gula tertinggi var. Alexandro pada konsentrasi 1600 ppm dan var. Melani pada $1800 \mathrm{ppm}$.

2. Tidak ada saling interaksi antara perlakuan varietas melon terhadap konsentrasi AB Mix yang diberikan pada semua variabel pengamatan (berat buah, volume buah, tebal daging dan kadar gula) kecuali pada jumlah bunga betina. Pengaruh yang ada disebabkan oleh faktor genetik dari varietas melon. 


\section{DAFTAR PUSTAKA}

Anonymous, 2012. Pacu Potensi Hortikultura Jatim dengan Pendekatan kawasan. https://swaranewsindonesia.wordpress.com/2012/04/23/pacu-potensihortikultura-jatim-dengan-pendekatan-kawasan/. Diakses tgl 5 Januari 2015.

Anonymous, 2014. Panduan Teknis Budidaya Melon.https://alamtani.com/ budidaya-melon/Diakses tgl 20 Januari 2016.

BPS, 2012. jemberkab.bps.go.id/. Diakses tgl 7 Januari 2016.

Gunawan, AW., 2009. Hidroponik Sayuran. Gramedia Pustaka, Jakarta.

Hendra, H.A dan Agus Andoko.2014. Bertanam Sayuran Hidroponik Ala Paktani Hydrofarm. Agro Media Pustaka. Jakarta.

Istiqomah, 2010. Menanam Hidroponik. Penerbit: Ganeca Exact.

Karsono, F., 2013.Exploring Classroom Hydroponic, Parung Farm, Bogor.

Lingga, P., 2006, Hidroponik Bercocok Tanam Tanpa Tanah. Penebar Sawadaya, Jakarta.

Lonardy, MV., 2006. Respon Tanaman Tomat (Lycopersicon esculentum Mill) Terhadap Suplai Senyawa Nitrogen dari Sumber Berbeda pada Sistem Hidroponik.Skripsi. Universitas Tadulako, Palu.

Nurlaeny, 2014.Teknologi Media Tanam dengan Sistem Hidroponik. Unpad Press. Bandung.

Rohmawati, U, Agus Karyanto, A., dan Hadi, M.S. 2007.Evaluasi Status Unsur Hara Nitrogen, Fosfor dan Kalium dengan Teknik Uji Cepat dan Karakter Mosfofisiologi Tanaman Melon (Cucumis melo L.). Unila.Lampung.

Rosliani dan Nani, 2005.Budidaya Tanaman Sayuran dengan Sistem Hidroponik. Balitsa, Bandung.

Siswanto, 2010.Meningkatkan Kadar Gula Buah Melon.Monograf.UPN Veteran Jawa Timur. Surabaya.

Sobir dan Firmansyah.2014. Berkebun Melon Unggul. Penebar Swadaya, Jakarta.

Sobir dan Siregar F.D., 2010.Budidaya Melon Unggul. Penebar Swadaya. Jakarta 